\title{
Effects of Instructional Multimedia Integrated Situational Approach on Students' Learning Achievement
}

\author{
Peng Cheng Wei ${ }^{1 *}$, Fangcheng He ${ }^{1}$, Sixing Huang ${ }^{1}$ \\ ${ }^{1}$ Chongqing University of Education, CHINA
}

Received 1 January $2018 \cdot$ Revised 31 March 2018 • Accepted 5 May 2018

\begin{abstract}
The instructional multimedia teaching effectiveness significantly enhances teaching quality that it does not simply break through the restriction on time and space, but could also receive immediate learning achievement, assist in traditional instruction, and provide learners with diverse learning and innovation ability. The advantage of instructional multimedia becomes the mainstream of education. With nonequivalent pretest posttest control group design, 198 students of Chongqing University of Education is proceeded the 15 -week ( 3 hours per week for total 45 hours) teaching experiment. The research results reveal remarkable effects of 1 .instructional multimedia on learning effect, 2.instructional multimedia on learning gain, 3.Situational Approach on learning effect, 4.Situational Approach on learning gain, 5.instructional multimedia integrated Situational Approach on the promotion of learning effect, and 6.instructional multimedia integrated Situational Approach on the enhancement of learning gain. According to the results, suggestions are proposed, expecting to provide students with the diverse and practical learning model to assist students in cultivating adequate basic abilities and allow students actively participating in discussions and solving problems in the instructional multimedia integrated Situational Approach teaching situation so as to enhance the learning motivation and promote the learning achievement.
\end{abstract}

Keywords: instructional multimedia, situational approach, learning achievement

\section{INTRODUCTION}

The popularity and diverse development of computer technology relies on the function of computer multimedia (John, Nwosu, \& Akorede, 2018). Accordingly, teaching and multimedia digital also appear critical influence. Current "instructional multimedia" becomes an alternative teaching tool beyond traditional learning. In terms of education, the teaching effectiveness significantly enhances teaching quality to break through the restriction on time and space and receive immediate learning achievement to assist in traditional instruction and provide learners with diverse learning and innovation ability. Besides, instructional multimedia is an important part of education, and the advantage of instructional multimedia would become the mainstream of education (Abbasi, Moeini, Shahriari, Ebrahimi \& Khoozani, 2018).

The Internet learning environment is not restricted on time and location and could provide various diversified materials and course contents for learners constructing knowledge through communication, discussion, and interaction \& exchange. The application of new technologies, like computer multimedia and the Internet, and new knowledge therefore could have learners reach learning achievement to manifest teaching quality.

A lot of children with low learning degree present laggard learning, could not fluently express the ideas in daily life, and even affect other learning and comprehension in life. With detailed analyses, inadequate cultural stimuli in the growth background and little meaningful communication and expressive interaction with family members and peers have school learning disconnect with the life. Such disconnected learning background and life experience have students not smoothly express the ideas. In this case, it is an urgent problem to enhance pupils' learning

(C) 2018 by the authors; licensee Modestum Ltd., UK. This article is an open access article distributed under the terms and conditions of the Creative Commons Attribution License (http://creativecommons.org/licenses/by/4.0/).

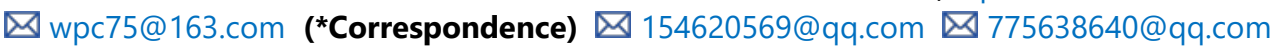




\section{Contribution of this paper to the literature}

- To promote teachers pursuing professional growth, teachers should be encouraged to engage in teaching research, find out problems and propose strategies for improvement, review and revise final evaluation, and constantly improve teaching methods.

- Either pictures or films could attract students' attention, but film watching is the first choice of most students. For this reason, local students, campus life, and hometown environment are the first choices as the situations in the application of instructional multimedia integrated Situational Approach to induce consonance.

- With the advance of technology, the popularity of networks, and the promotion of information software and hardware, a lot of products are looked for the possibility of being applied to education, and lots of development and research results would benefit children in the next generation.

achievement in class. Traditional education with unrealistic materials or teaching activities not arousing students' learning motivation is regarded as dangerous by many students. To improve traditionally cramming and didactic education and avoid disconnection between teaching contents and life experience, learner-centered education is proposed and Situational Approach emerges. Situational Approach stresses on "learning by doing" and "reflecting through doing". In the teaching context constructed by teachers, students have the opportunities to actively participate in learning and interaction that having students construct meaningful knowledge is the key point in situated teaching. Aiming at the effect of instructional multimedia integrated Situational Approach on students' learning achievement, a diverse and practical learning model is provided for assisting students in cultivating adequate basic abilities and allows students actively participating in discussion and solving problems in the instructional multimedia integrated Situational Approach teaching situation to enhance the learning motivation and promote the learning achievement.

\section{LITERATURE REVIEW}

\section{Instructional Multimedia}

It refers to the teaching methods being presented with computer controlled programs for learners directly contacting computers as the learning activity (Hong, 2016). Various media experience several times of evolution to appear the new term "computer multimedia", which refers to having computers integrate and organize various media elements, e.g. texts, images, films, animation, and music, and present the functions of storage, edition, and control (Lin, Huang, \& Chuang, 2015). It is an education concept and the teaching process presenting materials and controling individualized learning environment directly with the application of computer communication (Liu \& Lee, 2013). The characteristic of integrating images and audio-video of interactive instructional multimedia added communication and media technologies could generate diverse and open learning environment to further enhance the role in education reform (Adiguzel \& Orhan, 2017). Computers show the role of instructor to solve statistical analysis, word processing, data management, and program design as well as assist students in learning lessons for the individualized, mastery learning, or programmed instruction in remedial teaching $(\mathrm{Ng}, 2016)$. Instructional multimedia provides individualized instruction, aiming at students' individual abilities, to achieve the educational goal of teaching students accordance with the aptitude and remedy students' inadequate learning, rather than replacing formal teaching methods. In this case, instructional multimedia utilizes the visual situated space designed by new systems or new communication methods developed with electronic media digitalization for providing learners with better digital learning platforms (Deshmukh, Kaushik, \& Tayade, 2013). Sun et al. (2015) proposed that teachers specifically applied the functions of computer multimedia, such as films, images, presentation, and network, and broke away teachers' didactic teaching and knowledge delivery through texts and simple images in textbooks in the past. Järvelä et al. (2016) used instructional multimedia for learners' easy comprehension and effective achievement of teaching goals. Instructional multimedia has become the basic competence of teachers and would be the essential teaching mainstream in the future.

\section{Situational Approach}

Lee, Lee, Seo, and Choi (2015) regarded the idea of Situational Approach as placing learning in real or simulated situations to have students, through the interaction with the situations, more efficiently apply learned knowledge to real life. The integration into the situations facilitated students' positive and active learning, knowledge construction, and independent thinking in real life, while teachers changed the role from knowledge authorities into learners' partners. Mahmoodi, Kalantari, and Ghaslani (2014) mentioned that, in Situational Approach oriented learning, teachers were auxiliaries to set up scaffolds according to student needs, support and encourage students 
positively participating in activities and learning problem solving, remove scaffolds step by step according to students' enhancement of individual abilities, and promptly transfer learning responsibilities to learners. Cigdem (2015) stated that Situational Approach stressed on learning in real situations to construct meaningful knowledge; rich learning environments should be designed for teaching to lead learners evaluating and developing knowledge from various aspects. For the application to instruction, Situational Approach focused on environments for experiencing and learning as well as learning by doing and doing by learning in real situations to induce the learning motivation, and constantly establishing the meanings of knowledge through the interaction with situations. Learning environment conforming to above principles was regarded as situated learning environment (Rani, Nayak, \& Vyas, 2015), which emphasized the interaction between learners and situations that knowledge should be constructed in real situations and could not be separated from contexts (Hong \& Ditzler, 2013). The knowledge construction essentially allowed learners constructing knowledge and skills through observation, imitation, and actual participation in activities and situations in the activity, culture, and social context environment to really grasp knowledge (Stantchev, Prieto-González, \& Tamm, 2015). The knowledge transfer and the induction of learners' learning interests and learning motivation (Lin \& Tsai, 2016) required the integration of knowledge in situation cognition and learning situations. As a result, having learners present learning ideas and learning behaviors in proper situated environments could really learn knowledge.

\section{Learning Achievement}

Lin, Wen, Jou, and Wu (2014) regarded "learning" as individuals generating persistent changes of behaviors or behavior potential through practice or experience; and, learning achievement referred to learners' growth, effect, or achievement to goals preset by instructors after a period time of learning. DaRochaSeixas, Gomes, and DeMeloFilho (2016) pointed out learning achievement as the indicator to measure learners' learning outcome as well as a major item to evaluate teaching quality. Menon (2016) considered that learning achievement was an indicator to evaluate students' absorption of course contents, and teachers' teaching effectiveness could be judged according to students' test performance. Huang, Chen, Hwang, and Huang (2013) referred learning achievement to the evaluation or test of learners after completing learning activities to understand the achievement to the learned contents. Shadiev, Hwang, Huang, and Liu (2015) regarded learning achievement as the learning outcome and performance during the participation in activities. Hu and Driscoll (2013) proposed learning achievement as learners' performance on the participation in learning activities. Piccoli, Ahmad, and Lves (2001) pointed out learning achievement as learners' changes in cognition, affection, and skills after the teaching. Liaw and Huang (2013) referred learning achievement to students' behavioral changes before and after receiving education; and, the changes of deducting "starting behavior" before the education from "end behavior" after the education was the "direct" learning achievement of students. Relatively, "indirect" learning achievement referred to the effect being presented a period of time after students receiving education.

According to Han and Won (2016), learning achievement includes two dimensions in this study.

(1) Learning effect, containing test performance, time for schedule completion, and term performance

(2) Learning gain, covering learning satisfaction, achievement, and preference.

\section{METHOD AND SAMPLE}

\section{Research Hypothesis}

Wang et al. (2014) indicated that computers' rapid and accurate data acquisition could help learners realize abstract or inferred theories; applying computer simulation tools to learning was more flexible than traditional teaching activities, and the application of instructional multimedia could effectively enhance students' learning achievement (Adiguzel \& Orhan, 2017). Shorfuzzaman et al. (2014) mentioned that instructional multimedia combining software, hardware, and peripherals mainly presented on screens to enhance visual and hearing stimulation, showed discourse or interactivity functions to activate teaching and provide learning for learners. Hong (2016) described that teachers, when engaging in teaching, allowed learners proceeding learning with personal abilities and time, recorded the learning processes and schedule, and understood learners' learning conditions for the teaching improvement to largely improve students' learning achievement. Accordingly, the following hypotheses are proposed in this study.

H1: Instructional multimedia shows significant effects on learning effect.

H2: Instructional multimedia reveals remarkable effects on learning gain

In the research on how children learn vocabulary, Zhua, Aub, and Yatesb (2016) indicated that learning vocabulary through daily communication was faster and more efficient than learning from the definition and examples in dictionaries. Integrating learning into life experience had learning be more meaningful with better 
Table 1. Difference analysis of instructional multimedia

\begin{tabular}{ccccc}
\hline \multicolumn{2}{c}{ variable } & $\mathbf{F}$ & $\mathbf{P}$ & Scheffe post-hoc \\
\hline instructional & learning effect & 9.762 & $0.000^{* \star}$ & instructional multimedia $>$ traditional instruction \\
\cline { 2 - 5 } multimedia & learning gain & 10.133 & $0.000^{* \star}$ & instructional multimedia $>$ traditional instruction \\
\hline${ }^{*}$ stands for $p<0.05$ and ${ }^{* *}$ for $p<0.01$ & & &
\end{tabular}

learning achievement. Shyu and Jiang (2016) pointed out the mutual effect between real life situations and knowledge learning; students' learning required the support of familiar real contexts. After students comprehended the knowledge concept in contexts, knowledge was further applied to solve problems in life. Such a mutual effect relationship was a motive promotion model. Students' knowledge schema was pushed from simple and loose structure to complicated and exquisite to effectively enhance learning achievement. In the research on campus English environment use and learning satisfaction, Menon (2016) indicated that the establishment of campus English environment could actually assist in the promotion of English education, and students in schools with situated English learning environment showed higher use satisfaction and learning achievement than those in schools without the environment. With experimental research, Wang et al. (2014) integrated role play into Situational Approach for junior high school students' English teaching and discuss the learning achievement. The students were provided real English use situations, practiced English through role play, and creatively used English knowledge for facilitating learning transfer and enhancing learning motivation. The research results revealed notable progress of learning achievement in speaking and listening as well as enhancement of learning needs and attitudes. The following hypotheses are further proposed in this study.

H3: Situational Approach presents notable effects on learning effect.

H4: Situational Approach appears significant effects on learning gain.

$\mathrm{Xu}$, Perfetti, and Chang (2014) regarded computer multimedia as an effective tool to fulfill situated teaching, as it presented the design principle of the instructional theory. The linked story developed with well-designed software could induce learners' interests so that learners could reflect the learning process in the operation process and contact more accidental possibilities in the cycled execution to efficiently enhance learning achievement (Rani et al., 2015). Siadatya, Gaševićb, and Hatala (2016) mentioned that instructional multimedia integrated Situational Approach could achieve the goals of cognition, affection, skills, and life education as well as enhance learners' learning intention. Situated learning for instructional multimedia courses should be integrated into relevant tasks to integrate knowledge into learning situations for learners interacting and actively participating in learning activities from simple observation, imitation, and learning to knowledge and skills so as to achieve the interaction between simulated situational activities and learning situations and promote learning achievement (Lin \& Tsai, 2016). Sun et al. (2015) concluded that, in computer multimedia learning contents, learners should present learning ideas and behavioral goals, integrate and organize learning theories, and take the prior knowledge and individual difference into account to create quality learning environment and enhance learning intention and achievement. Accordingly, the following hypotheses are proposed in this study.

H5: Instructional multimedia integrated Situational Approach shows remarkable effects on learning effect.

H6: Instructional multimedia integrated Situational Approach reveals notable effects on learning gain.

\section{Research Object and Research Design}

To effectively achieve the research objective and test the research hypotheses, nonequivalent pretest posttest control group design is applied to the experiment in this study. Total 198 students of Chongqing University of Education is proceeded Situational Approach integrated instructional multimedia $2{ }_{2}$ experiment. The experiment is grouped Situational Approach (Situational Approach, traditional instruction) Xinstructional multimedia (instructional multimedia, traditional instruction) for 15-week ( 3 hours per week for total 45 hours) teaching research.

\section{ANALYSIS AND RESULT}

\section{Difference Analysis of Instructional Multimedia to Learning Achievement}

Analysis of Variance is applied to discuss the difference of instructional multimedia in learning effect and learning gain. From Table 1, instructional multimedia and traditional instruction appear significant differences in learning effect, instructional multimedia showing higher learning effect than traditional instruction, that H1 is supported. Furthermore, instructional multimedia and traditional instruction reveal significant differences in learning gain, instructional multimedia presenting higher learning gain than traditional instruction, that H2 is supported. 
Table 2. Difference analysis of Situational Approach

\begin{tabular}{ccccc}
\hline \multicolumn{2}{c}{ variable } & $\mathbf{F}$ & $\mathbf{P}$ & Scheffe post-hoc \\
\hline Situational & learning effect & 12.738 & $0.000^{* *}$ & Situational Approach $>$ traditional instruction \\
\cline { 2 - 5 } Approach & learning gain & 13.662 & $0.000^{* *}$ & Situational Approach $>$ traditional instruction \\
\hline${ }^{*}$ stands for $p<0.05$ and ${ }^{* *}$ for $p<0.01$ & & &
\end{tabular}

Table 3. Difference analysis of instructional multimedia integrated Situational Approach in learning achievement

\begin{tabular}{|c|c|c|c|c|c|c|}
\hline \multirow[t]{2}{*}{ variable } & \multicolumn{3}{|c|}{ learning effect } & \multicolumn{3}{|c|}{ learning gain } \\
\hline & $\mathbf{F}$ & $\mathbf{P}$ & Scheffe post-hoc & $\mathbf{F}$ & $\mathbf{P}$ & Scheffe post-hoc \\
\hline instructional multimedia & 9.762 & $0.000^{* *}$ & $\begin{array}{c}\text { instructional } \\
\text { multimedia }>\text { traditional } \\
\text { instruction }\end{array}$ & 10.133 & $0.000^{* *}$ & $\begin{array}{c}\text { instructional } \\
\text { multimedia>traditional } \\
\text { instruction }\end{array}$ \\
\hline Situational Approach & 12.738 & $0.000^{\star *}$ & $\begin{array}{c}\text { Situational } \\
\text { Approach }>\text { traditional } \\
\text { instruction }\end{array}$ & 13.662 & $0.000^{* *}$ & $\begin{array}{c}\text { Situational } \\
\text { Approach }>\text { traditional } \\
\text { instruction }\end{array}$ \\
\hline $\begin{array}{c}\text { instructional } \\
\text { multimedia*Situational } \\
\text { Approach }\end{array}$ & 33.527 & $0.000^{\star *}$ & $11>12>21>22$ & 36.435 & $0.000^{* *}$ & $11>21>12>22$ \\
\hline
\end{tabular}

\section{Difference Analysis of Situational Approach to Learning Achievement}

According to Analysis of Variance, the difference of Situational Approach in learning effect and learning gain is discussed. From Table 2, Situational Approach and traditional instruction show remarkable differences in learning effect, Situational Approach revealing higher learning effect than traditional instruction, that H3 is supported. Moreover, Situational Approach and traditional instruction appear notable differences in learning gain, Situational Approach showing higher learning gain than traditional instruction, than H4 is supported.

\section{Effects of Instructional Multimedia Integrated Situational Approach}

Analysis of Variance is utilized for discussing the difference of instructional multimedia integrated Situational Approach in learning achievement; besides, two-way Analysis of Variance is applied to discuss the interaction of instructional multimedia and Situational Approach to verify the enhancement of Situational Approach. From Table 3, instructional multimedia integrated Situational Approach presents the highest learning effect and learning gain that $\mathrm{H} 5$ and $\mathrm{H} 6$ are supported.

\section{CONCLUSION}

This study discusses the effect of instructional multimedia integrated Situational Approach on students' learning achievement. The results reveal that students, with instructional multimedia integrated Situational Approach, significantly enhance the learning achievement. Integrating instructional multimedia into situated teaching could activate school teaching to be more practical and create learning environments suitable for students. Besides, students spend a lot of time on campus that daily life environments are the best practice situations; both teachers and students are encouraged to largely use situated teaching. Besides, teaching with instructional multimedia integrated Situational Approach could help students' learning achievement that teachers could utilize instructional multimedia integrated Situational Approach for assisting students in comprehending abstract knowledge and linking with life experience through diverse materials and learning activities. Once students are accustomed to a single method, which would become standard learning activity, they would gradually lose the attraction. Instructional multimedia with pictures, audio-video pictures, or network resources could inspire learners' learning motive and reduce learning obstacles.

\section{RECOMMENDATIONS}

According to the research conclusion, the following suggestions are proposed in this study.

1. The rapid advance of information technology has changed learning styles. To satisfy teaching needs, educators should keep up with the time and well apply the advantages of computer multimedia to teaching. It is not to pursue novelty, but to consider the course needs and timely apply instructional multimedia to teaching activities. Learners, instructors, as well as teaching strategies and materials are the key factors in 
learning achievement. To promote teachers pursuing professional growth, teachers should be encouraged to engage in teaching research, find out problems and propose strategies for improvement, review and revise final evaluation, and constantly improve teaching methods.

2. Either pictures or films could attract students' attention, but film watching is the first choice of most students. For this reason, local students, campus life, and hometown environment are the first choices as the situations in the application of instructional multimedia integrated Situational Approach to induce consonance. Materials through instructional multimedia integrated Situational Approach could attract attention and increase learning interests; especially, materials related to student life could better induce experience link.

3. With the advance of technology, the popularity of networks, and the promotion of information software and hardware, a lot of products are looked for the possibility of being applied to education, and lots of development and research results would benefit children in the next generation. Urban-rural gap should be avoided in order to maintain education quality. Educational units therefore are suggested to draw complete and permanent information education plans, including the establishment or augmentation of wireless network on campus and basic establishment of personal computers and projectors.

\section{ACKNOWLEDGEMENTS}

Support by Chongqing Big Data Engineering Laboratory for Children, Chongqing Electronics Engineering Technology Research Center for Interactive Learning.

\section{REFERENCES}

Abbasi, S., Moeini, M., Shahriari, M., Ebrahimi, M., Khoozani, E. K. (2018). Designing and manufacturing of educational multimedia software for preventing coronary artery disease and its effects on modifying the risk factors in patients with coronary artery disease. Electronic Journal of General Medicine, 15(3), em22. https:// doi.org/10.29333/ejgm/85942

Adiguzel, A., \& Orhan, A. (2017). The relation between English learning students' levels of self-regulation and metacognitive skills and their English academic achievements. Journal of Education and Practice, 8(9), 115-125.

Cigdem, H. (2015). How does self-regulation affect computer-programming achievement in a blended context? Contemporary Educational Technology, 6(1), 19-37.

DaRochaSeixas, L., Gomes, A. S., \& DeMeloFilho, I. J. (2016). Effectiveness of gamification in the engagement of students. Computers in Human Behavior, 58, 48-63. https:/ / doi.org/10.1016/j.chb.2015.11.021

Deshmukh, V. J., Kaushik, S. S., \& Tayade, A. M. (2013). Cloud computing system for e-learning: A design and development approach. International Journal, 3(5), 1-9.

Han, I., \& Won, S. S. (2016). The use of a mobile learning management system and academic achievement of online students. Computers \& Education, 102, 79-89. https:/ / doi.org/10.1016/j.compedu.2016.07.003

Hong, E., \& Ditzler, C. (2013). Incorporating technology and web tools in creativity instruction. In K. H. Kim, J. C. Kaufman, J. Baer, \& B. Sriraman (Eds.), Creatively gifted students are not like other gifted students (pp. 17-37). Sense Publishers. https:/ / doi.org/10.1007/978-94-6209-149-8_3

Hong, Z. (2016). Factors influencing self-regulation in e-learning 2.0: Confirmatory factor model. Canadian Journal of Learning and Technology, 42(2), 21.

Hu, H., \& Driscoll, M. P. (2013). Self-regulation in e-learning environments: A remedy for community college? Journal of Educational Technology \& Society, 16(4), 171-184.

Huang, Y. M., Chen, H. C., Hwang, J. P., \& Huang, Y. M. (2013). Application of cloud technology, social networking sites and sensing technology to e-learning. In R. Huang, Kinshuk, \& J. M. Spector (Eds.), Reshaping Learning (pp. 343-364). New York: Springer Berlin Heidelberg. https://doi.org/10.1007/978-3-642-32301-0_15

Järvelä, S., Järvenoja, H., Malmberg, J., Isohätälä, J., \& Sobocinski, M. (2016). How do types of interaction and phases of self-regulated learning set a stage for collaborative engagement? Learning and Instruction, 43, 39-51. https:/ / doi.org/10.1016/j.learninstruc.2016.01.005

John, H. C., Nwosu, J. C., Akorede, O. J. (2018). Availability and Accessibility of Ict- Based Instructional Tools in Medical Colleges in Ogun State. European Journal of Health and Biology Education, 7(1), em4.

Lee, D. S., Lee, K. C., Seo, Y. W., \& Choi, D. Y. (2015). An analysis of shared leadership, diversity, and team creativity in an e-learning environment. Computers in Human Behavior, 42, 47-56. https:/ / doi.org/10.1016/j.chb.2013.10.064 
Liaw, S. S., \& Huang, M. M. (2013). Perceived satisfaction, perceived usefulness and interactive learning environments as predictors to self-regulation in e-learning environments. Computers $\mathcal{E}$ Education, 60(1), 1424. https:// doi.org/10.1016/j.compedu.2012.07.015

Lin, J. W., \& Tsai, C. W. (2016). The impact of an online project-based learning environment with group awareness support on students with different self-regulation levels: An extended-period experiment. Computers $\mathcal{E}$ Education, 99, 28-38. https:/ / doi.org/10.1016/j.compedu.2016.04.005

Lin, J. W., Huang, H. H., \& Chuang Y. S. (2015). The impacts of network centrality and self-regulation on an elearning environment with the support of social network awareness. British Journal of Educational Technology, 46(1), 32-44. https:/ / doi.org/10.1111/bjet.12120

Lin, Y. T., Wen, M. L., Jou, M., \& Wu, D. W. (2014). A cloud-based learning environment for developing student reflection abilities. Computers in Human Behavior, 32, 244-252. https:/ / doi.org/10.1016/j.chb.2013.12.014

Liu, S. H., \& Lee, G. G. (2013). Ipad infuse creativity in solid geometry teaching. The Turkish Online Journal of Educational Technology, 12(2), 177-192.

Mahmoodi, M. H., Kalantari, B., \& Ghaslani, R. (2014). Self-regulated learning (SRL), motivation and language achievement of Iranian EFL learners. Procedia - Social and Behavioral Sciences, 98, 1062-1068. https:// doi.org/10.1016/j.sbspro.2014.03.517

Menon, V. (2016). Working memory in children's math learning and its disruption in dyscalculia. Current Opinion in Behavioral Sciences, 10, 125-132. https://doi.org/10.1016/j.cobeha.2016.05.014

$\mathrm{Ng}$, E. W. (2016). Fostering pre-service teachers' self-regulated learning through self- and peer assessment of wiki projects. Computers $\mathcal{E}$ Education, 98, 180-191. https:// doi.org/10.1016/j.compedu.2016.03.015

Rani, M., Nayak, R., \& Vyas, O. P. (2015). An ontology-based adaptive personalized e-learning system, assisted by software agents on cloud storage. Knowledge-Based Systems, 90, 33-48. https:/ / doi.org/10.1016/j.knosys.2015.10.002

Shadiev, R., Hwang, W. Y., Huang, Y. M., \& Liu, T. Y. (2015). The impact of supported and annotated mobile learning on achievement and cognitive load. Journal of Educational Technology \& Society, 18(4), 53-69.

Shorfuzzaman, M., Alelaiwi, A., Masud, M., Hassan, M. M., \& Hossain, M. S. (2014). Usability of a cloud-based collaborative learning framework to improve learners' experience. Computers in Human Behavior, 51(8), 967976.

Shyu, H.-Y., \& Jiang, D.-J. (2016). Effects on Integrating Flipped Classroom into the Continuing Education for Primary and Secondary In-Service Teachers. Jiaoyu Yanjiu Yuekan(261), 46.

Siadatya, M., Gaševićb, D., \& Hatala, M. (2016). Measuring the impact of technological scaffolding interventions on micro-level processes of self-regulated workplace learning. Computers in Human Behavior, 59, 469-482. https:/ / doi.org/10.1016/j.chb.2016.02.025

Stantchev, V., Prieto-González, L., \& Tamm, G. (2015). Cloud computing service for knowledge assessment and studies recommendation in crowdsourcing and collaborative learning environments based on social network analysis. Computers in Human Behavior, 51, 762-770. https:/ / doi.org/10.1016/j.chb.2014.11.092

Sun, C. T., Ye, S. H., \& Wang, Y. J. (2015). Effects of commercial video games on cognitive elaboration of physical concepts. Computers and Education, 88, 169-181. https:/ / doi.org/10.1016/j.compedu.2015.05.002

Sun, J., Chang, K. Y., \& Chen, Y. H. (2015). GPS sensor-based mobile learning for English: An exploratory study on self-efficacy, self-regulation and student achievement. Research E Practice in Technology Enhanced Learning, 10(1), 1-18. https:/ / doi.org/10.1186/s41039-015-0024-y

Wang, C. Y., Wu, H. K., Wen-Yu Lee, S., Hwang, F. K., Chang, H. Y., Wu, Y. T., ... Lo, H. C. (2014). A review of research on technology-assisted school science laboratories. Journal of Educational Technology E Society, 17(2).

Wang, M., Chen, Y., \& Khan, M. J. (2014). Mobile cloud learning for higher education: A case study of Moodle in the cloud. The International Review of Research in Open and Distributed Learning, 15(2), 255-267. https:/ / doi.org/10.19173/irrodl.v15i2.1676

Xu, Y., Perfetti, C. A., \& Chang, L. Y. (2014). The effect of radical-based grouping in character learning in Chinese as a foreign language. The Modern Language Journal, 98(3), 773-793. https:/ / doi.org/10.1111/modl.12122

Zhua, Y., Aub, W., \& Yatesb, G. (2016). University students' self-control and self-regulated learning in a blended course. The Internet and Higher Education, 30. https:/ / doi.org/10.1016/j.iheduc.2016.04.001

\section{http://www.ejmste.com}

